\title{
Validity, reliability and accuracy of oscillometric devices, compared with Doppler ultrasound, for determination of the Ankle Brachial Index: an integrative review
}

\author{
Validade, confiabilidade e acurácia dos dispositivos oscilométricos em comparação ao \\ Doppler, para determinação do Índice Tornozelo-Braquial: revisão integrativa \\ Rita de Cassia Gengo e Silva', Vanessa Ferreira Amorim de Melo², Maria Aparecida de Medeiros Lima²
}

\begin{abstract}
Introduction: The conventional method for measuring the ankle-brachial index (ABI) requires a vascular Doppler machine and a trained professional, which is a barrier to the examination becoming more widely adopted across health services. For this reason, the possibility of substituting Doppler monitors for other types of device has been investigated. The objective of this study was to assess the validity, reliability and accuracy of taking ABI measurement using oscillometric devices and compare them to vascular Doppler. Methods: This is an integrative literature review of four articles. Results: There was very little uniformity between the four studies in terms of ample populations or the methodological procedures used to measure systolic pressures. The results for sensitivity, specificity and positive and negative predictive values varied and so did measures of reliability. Conclusions: The results of these studies do not provide a basis from which conclusions can be drawn on the validity, reliability or accuracy of employing oscillometric devices as a substitute for Doppler for determination of $A B \mid$.
\end{abstract}

Keywords: ankle-brachial index; peripheral arterial disease; arterial blood pressure measurement.

\begin{abstract}
Resumo
Introdução: A necessidade do Doppler vascular e da capacitação profissional para a realização do método convencional para medida do índice tornozelo-braquial (ITB) é uma barreira à disseminação desse tipo de avaliação nos serviços de saúde. Nesse contexto, a substituição do Doppler por outros dispositivos tem sido investigada. O objetivo deste trabalho foi avaliar a validade, a confiabilidade e a acurácia da determinação do ITB com o uso de dispositivo oscilométrico comparado ao Doppler vascular. Método: Esta revisão integrativa da literatura incluiu quatro artigos. Resultados: Os estudos foram bastante heterogêneos com relação à população estudada e aos procedimentos metodológicos para aferição das pressões sistólicas. Variações nos valores de sensibilidade e especificidade, e valores preditivos positivo e negativo foram observadas, assim como nas medidas de confiabilidade. Conclusão: Os resultados dos estudos não permitiram tecer conclusões acerca da validade, da confiabilidade e da acurácia da utilização do dispositivo oscilométrico em substituição ao Doppler, para determinação do ITB.
\end{abstract}

Palavras-chave: índice tornozelo-braço; doença arterial periférica; determinação da pressão arterial.

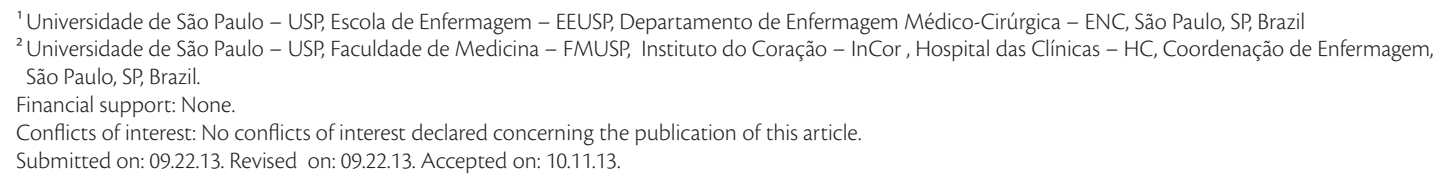




\section{INTRODUCTION}

Peripheral arterial occlusive disease (PAOD) of the lower limbs is an atherosclerotic syndrome with very high prevalence worldwide, especially among the over-fifties. ${ }^{1}$ It has been associated with reduced quality of life, with higher mortality and with occurrence of fatal and nonfatal ischemic events, such as cerebral vascular accidents, myocardial infarctions and angina. ${ }^{2,3}$ The clinical course of PAOD includes significant compromise of functionality related to lower limb symptoms, which vary from compromised ability to walk to claudication, pain at rest and gangrene. ${ }^{4}$

While PAOD has been well-described as a clinical entity, patients are still being under-diagnosed and under-treated, probably because more than half of PAOD patients are asymptomatic. Additionally, since this is a disease that primarily affects elderly people, patients may misinterpret or fail to describe their symptoms, believing them to be problems that are typical of their age. ${ }^{5}$

It is not therefore adequate to base screening and diagnosis of PAOD only on reported symptoms. One of the most important clinical methods available for PAOD screening is the ankle-brachial index (ABI), which has come to be considered a useful tool for evaluating the natural history of the disease in affected patients, in addition to also being useful for screening for PAOD among asymptomatic individuals. It is a simple, reproducible, noninvasive and low-cost method based on measuring systolic arterial blood pressure (SBP) in the extremities, with the aid of a vascular Doppler ultrasound machine. The method offers excellent measures of effectiveness when compared to arteriography for diagnosis of arterial occlusions greater than $50 \%$ of the lower extremity arterial bed. ${ }^{5,6}$

Despite its proven efficacy and utility for diagnosis of PAOD, the need for equipment (a vascular Doppler ultrasound machine) and for trained health professionals to operate it is a known barrier to adoption of this diagnostic tool in the many different clinical practice settings. ${ }^{7}$ In this context it becomes necessary to determine whether using different devices to measure SBP changes the ABI method's efficacy and reliability. The objective of this study was therefore to conduct an integrative literature review to evaluate the validity, reliability and accuracy of oscillometric devices compared with Doppler for taking measurements to determine ABI.

\section{METHODS}

This was an integrative literature review conducted over the following stages: identification of the subject; definition of the research hypothesis and research question; definition of the study inclusion and exclusion criteria; selection of the information to be extracted from the studies thus chosen; reading of studies chosen for integrative review and interpretation, presentation and discussion of results. ${ }^{8}$

The Patient, Intervention, Comparison, Outcomes strategy (PICO) ${ }^{9}$ was used to formulate the following question: "Are the ABI results obtained when oscillometric devices are used to measure SBP effective and reliable when compared with the results obtained using the gold standard method (Doppler) in patients with PAOD?'

The following databases and search strategies were used to identify articles:

- Pubmed: "Peripheral Arterial Disease OR Peripheral Vascular Diseases" AND "Blood Pressure Determination" AND "Reproducibility OR Validity OR Reliability"

- Europe Pubmed Central: "Peripheral Arterial Disease OR Peripheral Vascular Diseases" AND "Blood Pressure Determination" AND "Reproducibility OR Validity OR Reliability"

- Scopus: TITLE-ABS-KEY ("peripheral arterial disease" OR "peripheral vascular disease") AND TITLE-ABS-KEY ("ankle brachial index" OR "doppler" OR "oscillometric" OR "automated") AND TITLE-ABS-KEY ("validity" OR "reproducibility" OR "reliability" AND PUBYEAR > 2007

- Isi Web of Science: Topic = ("peripheral arterial disease" OR "peripheral vascular disease") AND Topic $=$ ("ankle brachial index" OR "Doppler" OR "oscillometric" OR "automated") AND Title = ("reproducibility" OR "validity" OR "reliability")

- Cochrane: "doença arterial periférica" AND "indice tornozelo-braquial", (Portuguese for "arterial peripheral disease" and "ankle-brachial index" respectively).

The studies chosen for this integrative review met the following criteria: they discuss the subject of interest; they are primary studies; their abstracts and full text are available in the databases listed above and they were published in Portuguese, English or Spanish in 2008 or later.

Studies were excluded if they compared oscillometric devices with the results of arteriography or other methods, if they were about non-conventional oscillometric devices (for example: $\mathrm{BOSO}^{\circledR}$, CASMED $^{\circledR}$ ), if they were about measurement of the toe-brachial index or if they were duplicated.

The flow diagram (Figure 1) summarizes the article selection process. 
A data collection instrument previously validated by $\mathrm{Ursi}^{10}$ was used to extract data from the articles chosen for the review. The instrument collected the following details: title of study; title of periodical; authors; country; language; year of publication; host institution of study; hospital; university; single institution or multicenter study; type of publication; methodological characteristics of study; objectives; sample type; treatment of data; interventions undertaken; results; analysis; implications; evidence level ${ }^{11}$; methodological rigor assessment, and identification of limitations.

The data thus extracted were analyzed descriptively, making it possible to assess evidence, provide a foundation for practice in both care and research and identify areas of the subject requiring further investigation.

\section{RESULTS}

Four primary studies met the eligibility criteria. All were published in English between 2008 and 2010, in periodicals with 2011 impact factors that varied from 0.427 to 1.531 . The studies were conducted in France (3) and the United Kingdom (1). The most important data from these studies are summarized in Table 1.
MacDonald, Froggatt, Lawrence and Blair ${ }^{12}$ conducted a study to compare the conventional Doppler method for obtaining ABI with an oscillometric device (OMRON 705CP), in order to verify whether the latter method is sufficiently accurate. They assessed 36 volunteers (69 years old, $69 \%$ male, $41.6 \%$ diabetic) who had been referred to a vascular clinic for investigation. A total of 72 lower limbs were analyzed, $30 \%$ of which had no signs or symptoms of PAOD. Blood pressures were measured at the ankle and arm for all volunteers using three different methods: (1) conventional aneroid sphygmomanometer and portable Doppler machine; (2) oscillometric device; and (3) oscillometric device and portable Doppler machine. A standard size cuff $(13 \mathrm{~cm})$ was used for all measurements. Measurements were taken by two experienced physicians and a vascular nurse. The authors found that when the oscillometric device was used alone it failed to detect ankle SBP in 11 out of the 16 cases in which patients had very low pressures. The mean difference between ABI results for methods 1 and 2 was $-0.021(95 \% \mathrm{CI}$ : $-0.056-0.014)$ and mean difference between $\mathrm{ABI}$ results with methods 1 and 3, was -0.015 (95\%CI: $-0.027-0.023)$. Method 2 offered good correlation with method $1(\mathrm{r}=0.769)$,

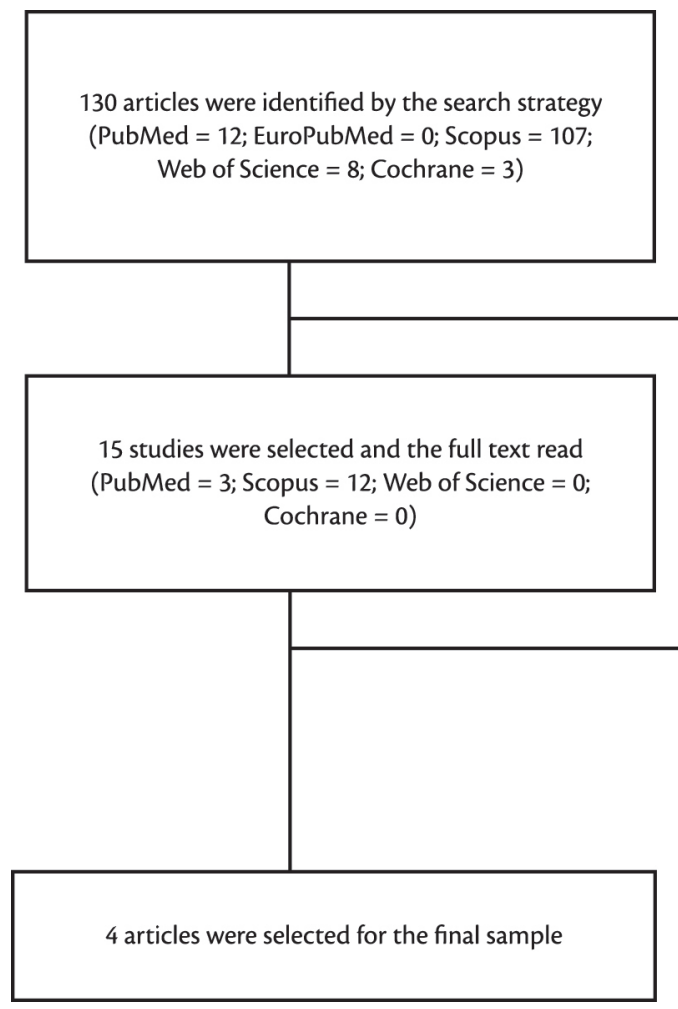

Figure 1. Flow diagram illustrating article selection. PAOD: peripheral arterial occlusive disease.

11 articles were excluded: 2 were no longer available online and the remainder were about the toe-brachial index, tested non-conventional oscillometric devices or did not use Doppler as gold standard for diagnosing PAOD. 


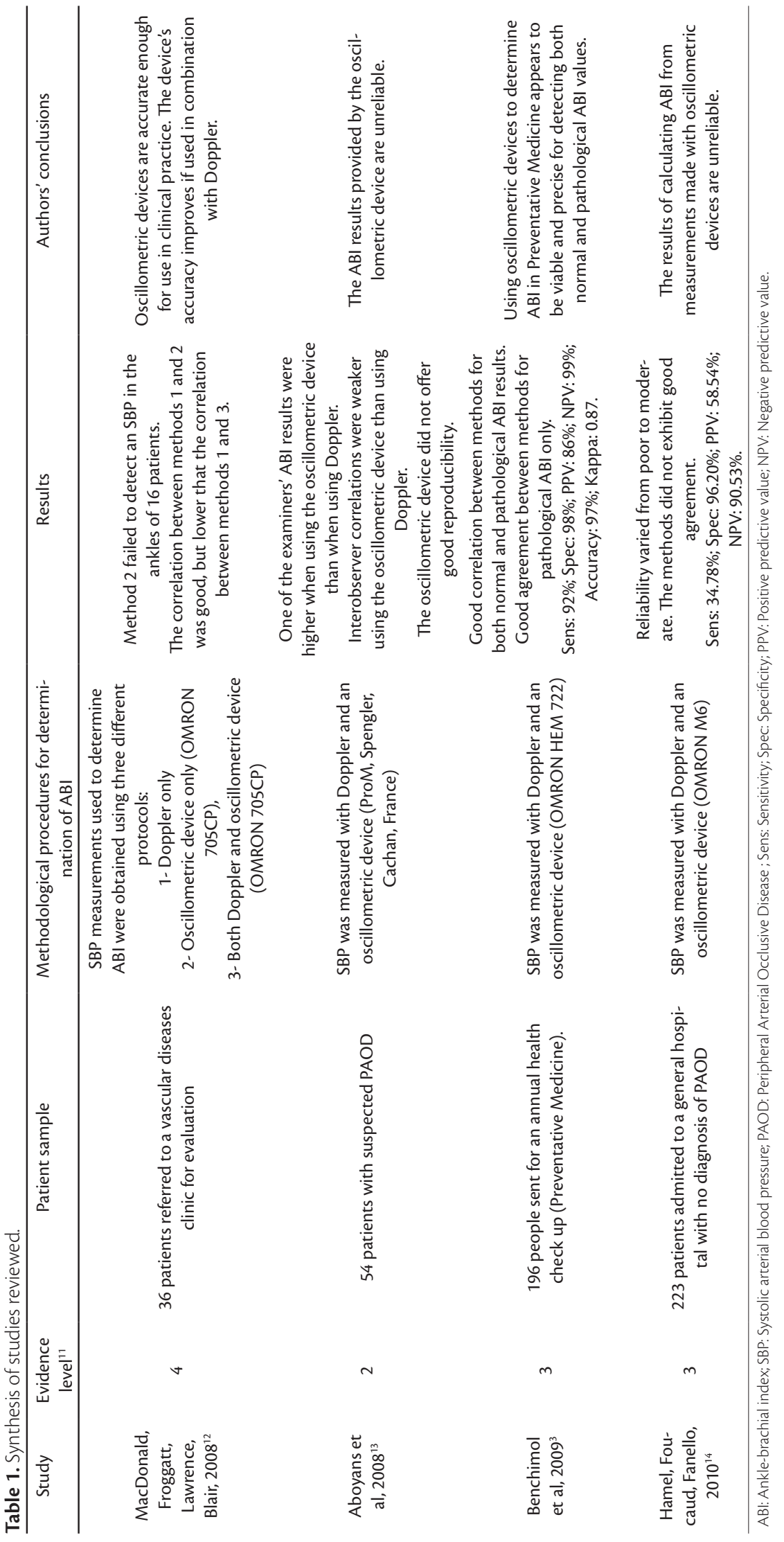


but the correlation between methods 1 and 3 was better $(r=0.899)$. These authors do not recommend using the oscillometric device alone, but conclude that it was accurate enough for use in clinical practice and that its accuracy improved when used in conjunction with the Doppler machine.

Aboyans et al. ${ }^{13}$ tested the validity and reliability of two alternative methods for determination of ABI (palpation of pulses and oscillometric devices) and compared them with the conventional Doppler method. They enrolled 54 people on the study $(58.2 \pm 17.1$ years; $51.8 \%$ do male sex $)$, ten of whom were healthy. The patients had been referred to a vascular laboratory for investigation of suspected intermittent claudication or subclinical PAOD and confirmed atherosclerotic disease or a major cardiovascular risk factor. Patients with confirmed PAOD were excluded. Each patient was assessed by two physicians, who took SBP measurements at all four limbs (brachial, pedal and posterior tibial arteries) by palpation, using Doppler and using an oscillometric device (ProM, Spengler, Cachan, France). The physicians were blinded to the SBP values, which were recorded by a vascular nurse. The first examiner repeated SBP measurements using palpation and Doppler. Brachial, pedal and posterior tibial arteries were examined. The same size cuff was used for all measurements. Doppler ABIs were calculated by dividing the highest pressure detected at each ankle by the mean of the SBPs detected in both arms. The results showed that obtaining ABIs using oscillometric devices was more specific than sensitive for detecting $\mathrm{ABI}<0.90$. It should also be emphasized that the two observers achieved very different sensitivity and specificity when determining ABI with the oscillometric device, with sensitivities of $76 \%$ vs. $58.3 \%$, and specificities of $96.4 \%$ vs. $89.3 \%$. One of these assessors produced significantly higher $\mathrm{ABI}$ results using the oscillometric device than using the Doppler method. The interobserver reproducibility for $\mathrm{ABI}$ determination with the oscillometric device was poor, when compared with the Doppler machine $(\mathrm{p}<0.05)$. These authors observed that the ABI values obtained with an oscillometric device are unreliable when assessing a mixed population including healthy people, patients at risk of PAOD and those with a suspicion of the disease and concluded that Doppler is indispensable for accurate measurements. They suggested that further research is required to develop a more simple method for measuring ABI.

A French study ${ }^{3}$ was conducted with the objective of assessing the viability, time taken and accuracy of using an oscillometric device (OMRON HM 722) for detecting pathological ABIs in people undergoing routine occupational health checks. Ankle-brachial indexes were determined using the oscillometric device, measuring all limbs in randomized order at the brachial and posterior tibial arteries. Cuff sizes were chosen according to the size of each subjects' limbs. The first SBP measurement at any site was disregarded. A total of 354 people were enrolled ( $50.5 \pm 6$ years, $74 \%$ males), $46 \%$ of whom had a history of smoking, $25 \%$ had hypertension, $6 \%$ had diabetes, $4 \%$ had coronary disease and $2 \%$ had PAOD. Both oscillometric and Doppler methods were used to determine ABIs for 196 people, 28 of whom had been identified in advance as having pathological ABIs, with the oscillometric device, and the remainder with normal ABIs. The method used to calculate $\mathrm{ABI}$ was to dividing the highest pressure reading from the ankle by the highest pressure in either arm. The methods had good correlation for calculating ABIs for both lower limbs. The Bland-Altman test did not show good agreement between the methods for these 196 people. For patients with pathological ABIs, there was good correlation and agreement between the methods. The oscillometric device achieved a sensitivity for detecting pathological ABIs of $92 \%$, with specificity of $98 \%$, a positive predictive value of $86 \%$ and a negative predictive value of $99 \%$. The oscillometric device achieved accuracy of $97 \%$ and the agreement was rated as excellent $($ Kappa $=0.87)$. These authors concluded that commercially-available oscillometric devices are viable, easy to use, rapid and precise for detecting normal and pathological ABIs.

The fourth study selected for review ${ }^{14}$ was conducted with the objective of testing the validity and reliability of using an oscillometric device (OMRON M6) to measure ABI, compared with measurement using Doppler. Cuff sizes were selected as appropriate to fit subjects' limbs. Measurements of SBP were taken at the brachial, pedal and posterior tibial arteries, all by a single examiner with experience in use of the Doppler technique. The ABI calculation used was to divide the highest ankle pressure by the highest pressure measured in the arms. A total of 243 patients (79.6 years, $48.4 \%$ males) admitted to a general hospital with no diagnosis of PAOD were assessed, including 6.3\% smokers, $16.8 \%$ diabetics, $58.4 \%$ with hypertension, $31.2 \%$ with hypercholesterolemia and $14 \%$ who were obese. Patients with noncompressible arteries (ABI $>1.30$ ) and with atrial fibrillation were excluded. There was a statistically significant difference 
between $\mathrm{ABI}$ measurements acquired using the two different methods, with a mean difference of 0.081 $(\mathrm{p}<0.0001)$. Reliability varied from poor to moderate and the Bland-Altman test showed that agreement was not good. The oscillometric device achieved $34.8 \%$ sensitivity for determining the presence of clinically detectable PAOD, specificity of $96.2 \%$ and positive and negative predictive values of $58.4 \%$ and $90.5 \%$ respectively. These authors concluded that, despite its practical advantages, the oscillometric device cannot be considered an alternative to Doppler for determination of ABI when screening undiagnosed populations for PAOD. In this case, $\mathrm{ABI}$ measurements obtained using the oscillometric device were unreliable.

\section{DISCUSSION}

This review collects together the results of studies that have assessed the validity, reliability and accuracy of ABI measurements using both Doppler and oscillometric devices. The decision was taken to only include studies that investigated conventional oscillometric devices because these are the most accessible type for use in many different clinical scenarios, particularly in primary care settings. It should also be pointed out that all of the oscillometric devices investigated in the studies included in this review have been validated for use in clinical practice. ${ }^{15}$

It is known that the $\mathrm{ABI}$ is an important clinical tool for screening for PAOD, because many patients with this disease are asymptomatic. ${ }^{6}$ A diagnosis of PAOD identifies patients as being at high risk of cardiovascular events and is therefore important from a public health perspective. ${ }^{6}$

The ABI is undeniably a reliable method when it is calculated from measurements taken using Doppler. However, there are several barriers to its use in clinical practice, including the need for training and continuous practice to ensure the technique is correctly performed, the cost of acquiring the Doppler machine itself and the time taken to conduct the procedure. ${ }^{14-16}$ This is why development of an alternative technique could contribute to widening the range of scenarios in which ABI is assessed.

Many different strategies have been tested for measuring $\mathrm{ABI},{ }^{13,17}$ but oscillometric devices are of particular interest because these machines have been widely adopted in clinical practice and, in general, health professionals learn to use them when they are first trained.

Four studies met the eligibility criteria for this integrative review, since they were all cross-sectional, observational and quantitative. However, they differ greatly in terms of the profiles of the patients studied and/or the methodological procedures used to compare the Doppler method with methods employing oscillometric devices, making it difficult to compare them against each other.

Two studies assessed populations at risk of PAOD or with suspected PAOD and one of them excluded patients with confirmed PAOD. With regard to the methodological procedures, in one of the studies the examiners were blinded to the ABI measurements taken. Failure to blind can introduce important bias into this type of study. Additionally, the number of pressure measurements taken also varied. While one study disregarded the first measurement taken, others took repeated measures. A lack of standardization of the procedures used to measure arterial blood pressure can also compromise comparison of results.

Three studies provided sensitivity, specificity, accuracy and positive and negative predictive values. However, their results were substantially different, which could be explained by the profiles of the patients studied and/or by the different methodological procedures used to select patients and to measure ABI.

The studies also conflict in terms of whether or not they concluded that oscillometric devices could be recommended for measuring ABI. While two studies categorically stated that oscillometric devices are unreliable for this application, the other two suggested that they could be used in clinical practice.

There are reports in the literature that employing oscillometric devices leads to overestimation of ankle pressures. Since low SBP in the lower limbs is a marker of severe deterioration in arterial blood flow, the ABIs of a high-risk population could therefore be incorrectly classified as normal. It should be remembered that oscillometric devices are designed to measure SBP within or above the range of normality and therefore when blood pressure is low the measurements may lack precision, with a direct and negative impact on the devices' reliability for measuring $\mathrm{ABI} .{ }^{3,18}$

\section{CONCLUSIONS}

This review has highlighted the scarcity of studies investigating the validity, reliability and accuracy of oscillometric devices for measuring $\mathrm{ABI}$, in comparison with the Doppler method. A series of differences in study populations and in the methodological procedures used to calculate ABIs meant that it was not possible to compare those studies that do exist. It can therefore be concluded 
that, to date, there is insufficient evidence to support substituting Doppler machines with oscillometric devices for determination of ABI.

\section{REFERENCES}

1. Fowkes F, Housley E, Cawood EH, Macintyre CC, Ruckley CV, Prescott RJ. Edinburgh Artery Study: prevalence of asymptomatic and symptomatic peripheral arterial disease in the general population. Int J Epidemiol. 1991;20:384-92. http://dx.doi. org/10.1093/ije/20.2.384

2. Pedrosa DFA, Pelegrin AKAP, Siqueira HBOM, Silva TCR, Colhado OCG, Sousa FAEFI. Avaliação da qualidade de vida em clientes com dor crônica isquêmica. Rev Latino-Am Enferm. 2011;19:67-72. http://dx.doi.org/10.1590/S0104-11692011000100010

3. Benchimol D, Pillois X, Benchimol A, et al. Accuracy of anklebrachial index using an automatic blood pressure device to detect peripheral artery disease in preventive medicine. Arch Cardiovasc Dis. 2009;102:519-24. http://dx.doi.org/10.1016/j. acvd.2009.03.011

4. Normas de orientação clínica para prevenção, diagnóstico e tratamento da doença arterial obstrutiva periférica (DAOP). Diagnóstico da doença arterial obstrutiva periférica (DAOP). J Vasc Bras. 2005;4:S222-8.

5. Meru AV, Mittra S, Thyagarajan B, Chugh A. Intermittent claudication: an overview. Atherosclerosis. 2006;187:221-37. http://dx.doi.org/10.1016/j.atherosclerosis.2005.11.027

6. Hirsch AT, Haskal ZJ, Hertzer NR, et al. ACC/AHA 2005 practice guidelines for the management of patients with peripheral arterial disease (lower extremity, renal, mesenteric, and abdominal aortic): a collaborative report from the American Association for Vascular Surgery/Society for Vascular Surgery, Society for Cardiovascular Angiography and Interventions, Society for Vascular Medicine and Biology, Society of Interventional Radiology, and the ACC/ AHA Task Force on Practice Guidelines (writing Committee to Develop http://dx.doi.org/10.1161/CIRCULATIONAHA.106.174 526Guidelines for the Management of Patients With Peripheral Arterial Disease): endorsed by the American Association of Cardiovascular and Pulmonary Rehabilitation; National Heart, Lung, and Blood Institute; Society for Vascular Nursing; TransAtlantic Inter-Society Consensus; and Vascular Disease Foundation. Circulation. 2006;113:463-654.

7. Vega J, Romani S, Garcipérez FJ, et al. Peripheral arterial disease: efficacy of the oscillometric method. Rev Esp.Cardiol. 2011;64:61921. http://dx.doi.org/10.1016/j.recesp.2010.10.019

8. Mendes KDS, Silveira RCCP, Galvão CM. Revisão integrativa: método de pesquisa pra a incorporação de evidências na saúde e na enfermagem. Texto Contexto Enferm. 2008;17:758-64. http:// dx.doi.org/10.1590/S0104-07072008000400018

9. Santos CMC, Pimenta CAM, Nobre MRC. A estratégia PICO para a construção da pergunta de pesquisa e busca de evidências. Rev Latino-Am Enferm. 2007;15:508-11. http://dx.doi.org/10.1590/ S0104-11692007000300023

10. Ursi ES. Prevenção de lesões de pele no perioperatório: revisão integrativa da literatura. [dissertação]. Ribeirão Preto: Universidade de São Paulo, Escola de Enfermagem de Ribeirão Preto; 2005 . [citado 2012 set 15]. http://www.teses.usp.br/teses/ disponiveis/22/22132/tde-18072005-095456/pt-br.php.

11. OCEBM Levels of Evidence Working Group. The Oxford 2011 Levels of Evidence. Oxford Centre for Evidence-Based Medicine. [citado 2012 set 15]. http://www.cebm.net/index.aspx?o=5653.
12. MacDonald E, Froggatt P, Lawrence G, Blair S. Are automated blood pressure monitors accurate enough to calculate the ankle brachial pressure index? J Clin Monit Comput 2008; 22:381-4. http://dx.doi.org/10.1007/s10877-008-9146-8

13. Aboyans V, Lacroix P, Doucet S, Preux PM, Criqui MH, Laskar M. Diagnosis of peripheral arterial disease in general practice: can the ankle-brachial index be measured either by pulse palpation or an automatic blood pressure device? Int J Clin Pract. 2008;62:1001-7. http://dx.doi.org/10.1111/j.1742-1241.2008.01784.x

14. Hamel JF, Foucaud D, Fanello S. Comparison of the automated oscillometric method with the gold standard doppler ultrasound method to access the ankle-brachial pressure index. Angiology. 2010;61:487-91. http://dx.doi.org/10.1177/0003319709360522

15. British Hypertension Society [internet]. Leicester: Britsh Hypertension Society. [atualizado 2012 jul 25; citado 2013 set 22]. http://www.bhsoc.org//index.php?clD $=246$.

16. Mohler ER, Treat-Jacobson D, Reilly MP, et al. Utility and barriers to performance of the ankle-brachial index in primary care practice. Vasc Med. 2004;9:253-60. http://dx.doi. org/10.1191/1358863x04vm559oa

17. Takahashi S, Shimbo T, Rahman $M$, et al. Validation of the auscultatory method for diagnosing peripheral arterial disease. Fam Pract. 2006;23:10-4. http://dx.doi.org/10.1093/fampra/ cmi034

18. Wohlfahit $P$, Ingrischová $M$, Krajcovechová $A$, et al. A nove oscillometric device for peripheral arterial disease screening in everyday practice. The Czech-post Monica study. Int Angiol. 2011;30:256-61.

Correspondence
Rita de Cassia Gengo e Silva
ENC- EEUSP
Av. Dr Eneas de Carvalho Aguiar, 419 - . $^{\circ}$ andar
CEP 05403-000 - São Paulo (SP), Brazil
Fone: +55 (11) 3061-7544/3061-8840
E-mail: rita.gengo@usp.br

Author's information

RCGS é Professora Doutora do Departamento de Enfermagem Médico-Cirúrgica da Escola de Enfermagem da Universidade de São Paulo (EEUSP)

VFAM é Enfermeira Assistencial da Coordenação de Enfermagem do Instituto do Coração (InCor) do Hospital das Clínicas da Faculdade de Medicina da Universidade de São Paulo (HCFMUSP)

MAML é ex-Aprimoranda do Programa de Enfermagem em

Cardiologia do Instituto do Coração (InCor) do Hospital das

Clínicas da Faculdade de Medicina da Universidade de São Paulo (HCFMUSP)

Author's contributions Conception and design: RCGS, VFAM, MAML Analysis and interpretation: RCGS, VFAM, MAML Data collection: VFAM, MAML Writing the article: RCGS Critical revision of the article: RCGS, VFAM, MAML Final approval of the article*: RCGS, VFAM, MAML Statistical analysis: N/A Overall responsibility: RCGS, VFAM, MAML

*All authors have read and approved of the final version of the article submitted to J Vasc Bras 